\title{
SPECIAL ARTICLE
}

\section{Campylobacter enteritis - the first five years}

Five years have passed since Campylobacter jejuni* became generally recognized as a common cause of acute diarrhoea (Skirrow, 1977) - although the essential scientific discovery which led to this had been made several years earlier (Butzler et al. 1973) - so this is an appropriate time to take stock of what has happened in that time and consider what we might usefully be doing to control the disease.

Even those engaged in early work in this field could hardly have foreseen the size of the problem posed by these bacteria. In Britain, campylobacter enteritis has emerged as the most frequently reported form of acute bacterial diarrhoea and there have been over a score of sizeable milk-borne outbreaks of infection, one involving some 3500 people (Jones et al. 1981). Contaminated municipal water supplies in two other technically advanced countries have caused major outbreaks of disease, each affecting over 2000 people (Mentzing, 1981; Vogt et al. 1982). We have seen how a military unit could be temporarily put out of action at a single stroke as a consequence of the preparation and consumption of contaminated chickens under field conditions (Brouwer et al. 1979). In the Third World $C$. jejuni is almost certainly a major cause of diarrhoeal disease in children; and although its role as an enteropathogen of animals is less clear, its importance as a cause of enzootic abortion in sheep, like its close relative C. fetus subsp. fetus, rests in no doubt. This is indeed an impressive citation for any parasite.

Some of these points will now be considered in more detail.

\section{THE SURVEILLANCE OF CAMPYLOBACTER INFECTIONS IN BRITAIN}

The results of five years' reporting of laboratory isolations of $C$. jejuni are shown in Fig. 1. These are reports from about 200 public health and hospital laboratories in England and Wales made to the Communicable Disease Surveillance Centre (Public Health Laboratory Service), London (CDSC). The initial rapid increase and subsequent more gradual rising trend can be attributed to the spread of interest among reporting laboratories and improved performance in the isolation of the organism. It is also possible that general practitioners may be more inclined to submit samples of faeces for culture now that the chances of a positive result are improved. Whatever the reasons for the increase, the number of campylobacter isolations in 1981 (12496) exceeded for the first time that of salmonellas (10745), and this inversion has continued into the first half of 1982 .

Two other features deserve comment. First, there is an obvious seasonal

* The term Campylobacter jejuni is used in the broad sense to include both $C$. jejuni and C. coli, unless otherwise stated. 


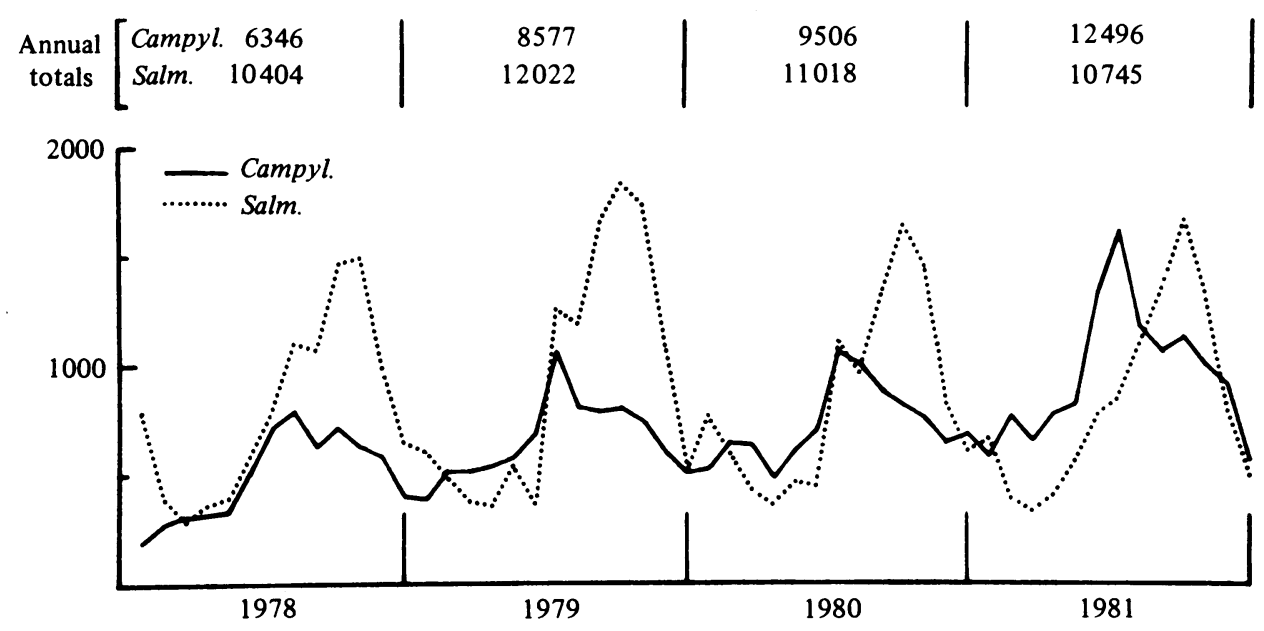

Fig. 1. Campylobacter and Salmonella isolations reported to CDSC from laboratories in England and Wales (4-weekly totals).

variation, with about twice as many infections reported in the third as in the first quarter of each year. The reasons for this are unknown, but it is a pattern that has been observed in Belgium, the Netherlands, Sweden, Canada, and the U.S.A. as well as in Britain. High ambient temperatures, which might favour the multiplication of campylobacters in food, are an unlikely explanation, for unlike salmonellas they tend to die rather than multiply at room temperature. Nor can travel abroad on summer holidays account for the trend, because it is still evident when imported infections are excluded from the figures (campylobacter enteritis is a common cause of traveller's diarrhoea). Secondly, there was an abrupt and exaggerated summer increase in 1981 that seems to have occurred throughout the country. The reasons for this are unknown, but there may be a clue in the fact that in the Worcester Royal Infirmary Laboratory, where isolates are biotyped routinely, the excess isolations were found to be $C$. jejuni biotype 2, which is found most often, though not exclusively, in domestic poultry (Skirrow \& Benjamin, 1982).

Analysis of CDSC returns by age shows that people of all ages are affected (range 1 day to 100 years) with a preponderance of infections in older children and young adults. Up to the age of 14 years, more isolations are reported in boys than girls (ratio 1.6:1) but the male excess in adults is only marginal $(1 \cdot 1: 1)$. There is a slight reversal of the ratio in those over 65 years old, which doubtless merely reflects the excess of old women in the population.

\section{Assessment of morbidity}

The CDSC figures provide a base from which to estimate the number of working days lost due to campylobacter enteritis. Allowing for the proportion of patients not in employment and assuming an average incapacity of three days (a conservative estimate), the figure approaches 20000 working days per year. Of course this is 
a minimum figure that does not take into account all the unreported or undiagnosed infections. Something nearer the true figure can be gained from a study carried out on a defined population by Kendall \& Tanner (1982). They showed that $20 \%$ of consultations for enteritis in general practice were associated with campylobacter infection and that the projected rate of campylobacter enteritis was $1.1 \%$ of the population per year. This works out at about 600000 cases per year for the whole of the United Kingdom, which is some 40 times the figure derived from laboratory reports. Even if their figures are high relative to the rest of the country, this still represents an enormous morbidity. On top of this there is the misery and inconvenience suffered by patients whether or not they are employed. Mortality is minimal, but there is a small yet significant minority of patients who suffer complications: children may have grand-mal seizures; patients may end up in hospital with 'pseudo-appendicitis'; and others may be incapacitated by reactive arthritis that lingers on long after the acute illness has passed. This all adds up to a substantial drain on economic and health resources.

\section{RESERVOIRS, SOURCES AND TRANSMISSION OF INFECTION}

The control of any communicable disease depends on a thorough knowledge of its epidemiology - reservoirs, sources, and modes of transmission of the agent in question. Only when these are known can effective measures be directed at reducing the reservoir or interrupting transmission. With campylobacter enteritis it is clear that we are dealing with a zoonosis: animals constitute the main reservoir of infection, whereas man - at least in technically developed countries - is a relatively unimportant secondary reservoir either for direct or indirect transmission; no long-term carrier has been described, campylobacters disappear from the stools within a few weeks of illness, and transmission from person to person is uncommon unless the index case is a young child. Secondary cases in common-source outbreaks are usually notable for their absence.

A wide variety of animals, both wild and domestic, can harbour C.jejunifrom kangaroos to camels among mammals, and Peruvian penguins to Blue-crowned Motmots among birds (Bauwens \& Meurichy, 1981 ; Luechtefeld, Cambre \& Wang, 1981). Wild birds probably constitute the main natural reservoir of infection. From 20 to $70 \%$ of seagulls (Larus) have been found to harbour campylobacters, many of which are strains of $C$.jejuni indistinguishable from those found in sheep, cattle, poultry and man (Skirrow \& Benjamin, 1980; Fenlon, 1981). C.jejuni has also been found in $35 \%$ of migratory waterfowl in the U.S.A. (Luechtefeld et al. 1980), and in $45 \%$ of rooks and $50 \%$ of urban pigeons in Britain (Fenlon, 1981). Wild birds are probably the main source of campylobacters that can regularly be found in natural waters (Knill, Suckling \& Pearson, 1982), but other animals and man doubtless contribute their share under the right circumstances. Although campylobacters can survive in water for several weeks at low temperatures (Blaser et al. 1980), they are never found in the absence of faecal coliforms (Knill, Suckling \& Pearson, 1982), so it is unlikely that they exist as independent saprophytes. 


\section{Water and environment as a source of infection}

Untreated natural water must always be regarded as a potential source of infection for both man and animals. Apart from the evidence of two major waterborne outbreaks mentioned above, a history of the accidental or deliberate ingestion of water from lakes, rivers, streams, or even the sea, while engaged in outdoor activities crops up too often among patients suffering from campylobacter enteritis to dismiss as coincidental (e.g. Pearson et al. 1982). A particularly interesting prospective study carried out by Khan (1982) showed a build-up of a single serotype of $C$. jejuni first in waterfowl and the mud of a riverside meadow in which they lived, then in five dogs (all with diarrhoea) that frequented the area, and finally in seven of their human contacts, all within a period of six weeks. The sequence, waterfowl-environment-dog-man, was not proved, but the circumstances are certainly suggestive.

\section{Principal animal sources}

The animals of special importance as sources of human infection are probably poultry, cattle, sheep, pigs and dogs, but not necessarily in that order of importance. Infection can be acquired through direct contact with infected animals, but this accounts for only a small minority of infections. Contact may be occupational, as in farmers, veterinarians and those engaged in meat processing (Jones \& Robinson, 1981), or domestic, in which case the animal concerned is almost always a newly acquired family puppy, or occasionally a kitten, which is itself suffering from campylobacter enteritis (Skirrow, 1981). But most day-to-day infections are in patients without any direct contact with animals, so indirect pathways of infection presumably operate in these cases. Information is lacking, but it is likely that transmission is mainly through the food chain from raw animal products: milk, meat and offal.

Milk. Raw cow's milk has unquestionably been incriminated as a vehicle of infection. In Britain virtually all major outbreaks of campylobacter enteritis have been associated with the distribution of raw or improperly pasteurized cow's milk (Robinson \& Jones, 1981). It has also been shown that many who habitually drink raw milk have campylobacter antibody in their blood (Jones, Robinson \& Eldridge, 1981). The source of the organism is thought to be the dairy cows themselves, but it is not known whether they get into the milk through faecal contamination or by excretion from a cow suffering from campylobacter mastitis. C. jejuni mastitis has been produced experimentally (Lander \& Gill, 1980) but not reported as a natural infection; if it does occur naturally it probably takes the form of a sporadic transient infection involving single animals, unlike the common infectious forms of mastitis due to pyogenic cocci or coliforms. This is something that should be sought and investigated. It should be emphasized that in the 13 outbreaks reviewed by Robinson \& Jones (1981) the methods used by most of the dairy farms were blameless, so good hygienic practice cannot be relied upon to prevent infection - pasteurization or other heat treatment is the only sure remedy. It is also worth pointing out that some of the outbreaks arose because severe winter 
weather caused breakdowns of pasteurization either from power failures or from disruption of the transport of milk to pasteurizing plants (e.g. Porter \& Reid, 1980).

Meat and offal. Contaminated meat and offal can cause infection in any of three ways: the contaminated product itself may be eaten raw or undercooked; the person preparing the food may become self-infected through handling the raw product; or other foods that are to be eaten raw or without further cooking may become cross-contaminated from the raw product. In the case of campylobacters evidence indicates that all three methods can operate. Here there is a difference from salmonellosis in that multiplication of salmonellas in the food is usually a prerequisite of clinical infection. Indirect evidence suggests a much smaller infective dose for campylobacters; it is known that a dose of 500 organisms caused infection in a human volunteer (Robinson, 1981).

Poultry constitute by far the largest potential source of campylobacters, but it does not follow that they constitute the main source. $C$. jejuni can be cultured from most chicken and turkey carcasses sold at retail outlets, not only in Britain (Simmons \& Gibbs, 1979) but in the Netherlands (Hartog \& De Boer, 1982), Sweden (Svedhem, Kaijser \& Sjögren, 1981), Yugoslavia (Mehle, Gubina \& Gliha, 1982), the U.S.A. (Luechtefeld \& Wang, 1981 ; Grant, Richardson \& Bokkenheuser, 1980; Christopher, Smith \& Vanderzant, 1982), Canada (Park et al. 1981), South Africa (Richardson \& Koornhof, 1979), and Australia (Smeltzer, 1981). The consumption of raw or undercooked chickens has been implicated in at least four outbreaks of campylobacter enteritis (Brouwer et al. 1979; Skirrow, Fidoe \& Jones, 1981 ; Itoh et al. 1982; Mouton et al. 1982), and Kist (1982) found that significantly more patients with campylobacter enteritis had eaten poultry, particularly broiler chickens, within $48 \mathrm{~h}$ of the onset of illness compared with healthy controls. In a similar survey in the Netherlands, Severin (1982) found that infection was more often associated with shorter cooking times for chickens (fondue, barbecue, gourmet) than longer ones (baking, roasting, boiling). Norkrans \& Svedhem (1982) found that more patients than control subjects had prepared chicken within four days of becoming ill and that they were the only persons in their households to become infected even though all had eaten the prepared chickens.

Red meats are in general much less frequently contaminated. Although campylobacters can regularly be found on abattoir carcasses (Stern, 1981; Bolton, Dawkins \& Robertson, 1982 ; Hudson \& Roberts, 1982; Turnbull \& Rose, 1982), contamination falls to low levels by the time meats reach retail outlets. In a large British survey campylobacters were cultured from only $1 \%$ of retail raw red meats (Turnbull \& Rose, 1982), and Bolton, Dawkins \& Robertson (1982), despite the use of more sensitive culture techniques, failed to detect campylobacters in any of 270 meat swabs taken in wholesale and retail butchers' premises. A single outbreak of infection attributed to the consumption of raw beef hamburgers has been reported (Oosterom et al. 1980). However, pigs may be an important source of infection in certain European countries where salted, smoked and rare-cooked pork and offal are popular foods. High contamination rates for such products have been found in Germany (Sticht-Groh, 1982), and it may be significant that more strains of $C$. coli-a species particularly associated with pigs - have been found 
among human campylobacter isolates from such countries than in Britain, where C. coli accounts for only about $5 \%$ of human isolates (Skirrow \& Benjamin, 1982).

Raw clams were apparently responsible for an outbreak of campylobacter enteritis in Japan (Itoh et al. 1982).

Cross-contamination of foods not normally associated with campylobacters is probably a frequent mode of infection, but it is almost impossible to prove. It is hard to conceive of any other way in which the icing of a birthday cake could have been implicated in an outbreak reported from the U.S.A. (Blaser et al. 1981). De Wit, Broekhuizen \& Kampelmacher (1976) showed that contamination of the kitchen environment from frozen broilers inoculated with a marker strain of Escherichia coli could be extensive, and there is no reason why campylobacters should not be spread in the same manner.

\section{PREVENTION AND CONTROL}

There are certain obvious preventive measures that follow logically from what has been said. They are not specific for campylobacters, but they would almost certainly give a good measure of control if widely applied.

(1) All milk sold to the public should be pasteurized, or otherwise heat-treated. Pasteurization kills C. jejuni (Gill, Bates \& Lander, 1981; Waterman, 1982).

(2) Public water supplies should be adequately purified, preferably by chlorination. This is the norm in many countries such as Britain, but the possibility of contamination from faults in distribution systems should be borne in mind. For example the storage tanks that supply many hospital and industrial sites could become contaminated from birds or other small animals if not properly designed and maintained.

(3) Good hygiene should be practised by those engaged in animal husbandry or meat processing. The general public should be encouraged to pay particular attention to hand washing when dealing with sick household pets, which should be kept away from young children.

(4) The following rules of hygiene should be applied in kitchens and food preparation areas: raw animal products should be kept and dealt with separately from other foods; good personal hygiene should be practised when handling raw animal products; cooking should be adequate. These rules should be mandatory for catering establishments and promoted among the general public.

With regard to the exclusion of infected food handlers, no person suffering from diarrhoea (from whatever cause) should be allowed to prepare food for public consumption. However, the low transmissibility of $C$. jejuni and its inability to multiply in food at room temperatures are reasons for not routinely insisting on bacteriological clearance of campylobacter excreters once their stools have become formed again. Norkrans \& Svedhem (1982) found no evidence of infection among children at a day centre or members of a hospital who had eaten food prepared over a period of 10 days by two cooks who were excreting $C$. jejuni. But there may be occasional exceptions to this general rule, and in cases of difficulty excretion can usually be eliminated by a short course of erythromycin.

On the assumption that most human infections are food-borne and associated 
with raw animal products, the prevention of infection in animals bred for food would be the ideal solution. What are the prospects for providing campylobacter-free chickens, for example? Colonization of broiler flocks has been observed at an early stage of development - sometimes within a few days of hatching - but it is not known how infection is introduced into the closed environment of broiler production units; it is not apparently through egg transmission either by infection of the embryo or by contamination of the shell (Cruickshank et al. 1982). Since water supplies to such units are usually piped directly from mains supplies, and since $C$. jejuni is unlikely to survive in dried feeds, one wonders if the organism is introduced on the boots and clothing of human attendants or from small rodents and passerine birds gaining access through holes or ventilation ports. These are areas for investigation, and it is the minority of flocks that remain free from infection which might be studied most profitably. Ways of reducing contamination in poultry processing establishments might also be improved. Mechanical eviscerating processes cause widespread contamination of the surface of carcasses with bowel flora including campylobacters (Luechtefeld \& Wang, 1981; Hartog \& De Boer, 1982; Mehle, Gubina \& Gliha, 1982). Subsequent washing in chlorinated water cannot be relied upon to remove them, for Luechtefeld \& Wang (1981) and Mehle, Gubina \& Gliha (1982) found it produced only moderate reduction in contamination even though Christopher, Smith \& Vanderzant (1982) did find the method to be effective. Vats containing unchlorinated or inadequately chlorinated water result in gross cross-contamination; spray cooling and rinsing methods are preferable. Freezing of carcasses causes some reduction in numbers of campylobacters, but once in the frozen state they can survive for several months. To summarize, we can say that there is no immediate prospect for the prevention of infection in poultry. More data are required before any prospects for control can be assessed and the costs balanced against the benefits.

So where do we go from here? It is unlikely that there will be any major advances in the field of campylobacter epidemiology until we have a comprehensive and practical strain identification scheme. This is the most pressing need. Several serological typing schemes are under development, and some 60 serogroups based on heat-stable somatic antigens have been described. Serogrouping has already been applied in field studies to good effect (e.g. Jones, Robinson \& Eldridge, 1981), and one looks forward to the time when antisera become more widely available. The application of serotyping in medical and veterinary laboratories over the next five years should provide a future reviewer with some interesting material.

\section{B. SkIRRow \\ Worcester Royal Infirmary, Castle Street, Worcester WR1 $3 A S$}

I wish to thank Dr N. S. Galbraith for permission to publish data collected by the Communicable Disease Surveillance Centre (Public Health Laboratory Service), London. 


\section{REFERENCES}

Bauwens, L. \& De Meurichy, W. (1981). The occurrence of thermophilic campylobacters in zoo animals. Acta Zoologica et Pathologica Antverpiensia No. 76, 181-189.

Blaser, M. J., Checko, P., Bopp, C. \& Hughes, J. (1981). Foodborne Campylobacter enteritis. Abstracts of the Annual Meeting of the American Society for Microbiology 1981, p. 264.

Blaser, M. J., Hardesty, H. L., Powers, B. \& Wang, W. L. (1980). Survival of Campylobacter fetus subsp. jejuni in biological milieus. Journal of Clinical Microbiology 11, 309-313.

Bolton, F. J., Dawkins, H. C. \& Robertson, L. (1982). Campylobacter jejuni/coli in abattoirs and butchers' shops. Journal of Infection 4, 243-245.

Brouwer, R., Mertens, M. J. A., Siem, T. H. \& Katchaki, J. (1979). An explosive outbreak of Campylobacter enteritis in soldiers. Antonie van Leeuwenhoek 45, 517-519.

Butzler, J. P., Dekeyser, P., Detrain, M. \& Dehaen, F. (1973). Related vibrio in stools. Journal of Pediatrics 82, 493-495.

Christopher, F. M., Smith, G. C. \& Vanderzant, C. (1982). Examination of poultry giblets, raw milk and meat for Campylobacter fetus subsp. jejuni. Journal of Food Protection 45, 260-262.

Cruickshank, J. G., Egglestone, S. I., Gawler, A. H. L. \& Lanning, D. G. (1982). Campylobacter jejuni and the broiler chicken process. In Campylobacter: Epidemiology, Pathogenesis and Biochemistry (ed. D. G. Newell), pp. 263-266. Lancaster: MTP Press.

De Wit, J. C., Broekruizen, G. \& Kampelmacher, E. H. (1976). Kruisbesmetting bij de bereiding van diepvrieskuikens in de keuken. [Cross-contamination in the preparation of deep-frozen chickens in the kitchen.] Voeding 39, 208-210.

Fenlon, D. R. (1981). Birds as vectors of enteric pathogenic bacteria. Journal of Applied Bacteriology 51, xiii-xiv.

Gill, K. P. W., Bates, P. G. \& Lander, K. P. (1981). The effect of pasteurization on the survival of Campylobacter species in milk. British Veterinary Journal 137, 578-584.

Grant, I. H., Richardson, N. J. \& Bokkenheuser, V. D. (1980). Broiler chickens as potential source of Campylobacter infections in humans. Journal of Clinical Microbiology 11, 508-510.

Hartog, B. J. \& De Boer, E. (1982). Campylobacter jejuni in poultry products from retail outlets and in poultry slaughterhouses. In Campylobacter: Epidemiology, Pathogenesis and Biochemistry (ed. D. G. Newell), p. 270. Lancaster: MTP Press.

Hudson, W. R. \& Roberts, T. A. (1982). The occurrence of campylobacter on commercial red-meat carcasses from an abattoir. In Campylobacter: Epidemiology, Pathogenesis and Biochemistry (ed. D. G. Newell), p. 273. Lancaster: MTP Press.

Itoh, T., Saito, K., Yanagawa, Y., Sakai, S. \& Ohashi, M. (1982). Campylobacter enteritis in Tokyo. In Campylobacter: Epidemiology, Pathogenesis and Biochemistry (ed. D. G. Newell), pp. 5-12. Lancaster: MTP Press.

Jones, D. M. \& Robinson, D. A. (1981). Complement fixing antibody to $C$. jejuni in poultry and meat process workers. Lancet i, 440.

Jones, D. M., Robinson, D. A. \& Eldridge, J. (1981). Serological studies in two outbreaks of Campylobacter jejuni infection. Journal of Hygiene 87, 163-170.

Jones, P. H., Willis, A. T., Robinson, D. A., Skirrow, M. B. \& Josephs, D. S. (1981). Campylobacter enteritis associated with the consumption of free school milk. Journal of Hygiene 87, 155-162.

Kendall, E. J. C. \& TANNER, E. I. (1982). Campylobacter enteritis in general practice. Journal of Hygiene 88, 155-163.

KHAN, M. S. (1982). An epidemiological study of a campylobacter enteritis outbreak involving dogs and man. In Campylobacter: Epidemiology, Pathogenesis and Biochemistry (ed. D. G. Newell), pp. 256-258. Lancaster: MTP Press.

KIST, M. (1982). Campylobacter enteritis: epidemiological and clinical data from recent isolations in the region of Freiburg, West Germany. In Campylobacter: Epidemiology, Pathogenesis and Biochemistry (ed. D. G. Newell), pp. 138-143. Lancaster: MTP Press.

Knill, M. J., Suckling, W. G. \& Pearson, A. D. (1982). Campylobacters from water. In Campylobacter: Epidemiology, Pathogenesis and Biochemistry (ed. D. G. Newell), pp. 281-284. Lancaster: MTP Press.

LANDER, K. P. \& GiLL, K. P. W. (1980). Experimental infection of the bovine udder with Campylobacter coli/jejuni. Journal of Hygiene 84, 421-428. 
Luechtefeld, N. W., Blaser, M. J., Reller, L. B. \& Wang, W. L. (1980). Isolation of Campylobacter fetus subsp. jejuni from migratory waterfowl. Journal of Clinical Microbiology 12, 406-408.

Luechtefeld, N. W., Cambre, R. C. \& Wang, W. L. (1981). Isolation of Campylobacter fetus subsp. jejuni from zoo animals. Journal of the American Veterinary Medical Association 179, $1119-1122$.

Luechtefeld, N. W. \& WANG, W. L. (1981). Campylobacter fetus subsp. jejuni in a turkey processing plant. Journal of Clinical Microbiology 13, 266-268.

Mehle, J., Gubina, M. \& Gliha, B. (1982). Contamination of chicken meat with Campylobacter jejuni during the process of industrial slaughter. In Campylobacter: Epidemiology, Pathogenesis and Biochemistry (ed. D. G. Newell), pp. 267-269. Lancaster: MTP Press.

Mentzing, L. O. (1981). Waterborne outbreaks of campylobacter enteritis in central Sweden. Lancet ii, 352.

Mouton, R. P., Veltkamp, J. J., Lauwers, S. \& Butzler, J. P. (1982). Analysis of a small outbreak of campylobacter infections with high morbidity. In Campylobacter: Epidemiology, Pathogenesis and Biochemistry (ed. D. G. Newell), pp. 129-134. Lancaster: MTP Press.

Norkrans, G. \& Svedhem, А. (1982). Epidemiological aspects of Campylobacter jejuni enteritis. Journal of Hygiene 89, 163-170.

Oosterom, J., Beckers, H. J., Van Noorle Jansen, L. M. \& Van Schothorst, M. (1980). Een explosie van Campylobacter-infectie in een kazerne, waarschijnlijk veroorzaakt door rauwe tartaar. Nederlands Tijdschrift voor Geneeskunde 124, 1631-1633.

Park, C. E., Stankiewicz, Z. K., Lovett, J. \& Hunt, J. (1981). Incidence of Campylobacter jejuni in fresh eviscerated whole market chickens. Canadian Journal of Microbiology 27, 841-842.

Pearson, A. D., Drake, D. P., Brookfield, D., O'Connel, S., Suckling, W. G., Knill, M. J., WARE, E. \& KNOTT, J. R. (1982). Campylobacter infections in patients presenting with diarrhoea, mesenteric adenitis and appendicitis. In Campylobacter: Epidemiology, Pathogenesis and Biochemistry (ed. D. G. Newell), pp. 147-151. Lancaster: MTP Press.

Porter, I. A. \& Reid, T. M. S. (1980). A milk-borne outbreak of Campylobacter infection. Journal of Hygiene 84, 414-419.

Richardson, N. J. \& Koornhof, H. J. (1979). Campylobacter infections in Soweto. South African Medical Journal 55, 73-74.

Robinson, D. A. (1981). Infective dose of Campylobacter jejuni in milk. British Medical Journal $282,1584$.

Robinson, D. A. \& Jones, D. M. (1981). Milk-borne campylobacter infection. British Medical Journal 282, 1374-1376.

Severin, W. P. J. (1982). Epidemiology of campylobacter infection. In Campylobacter: Epidemiology, Pathogenesis and Biochemistry (ed. D. G. Newell), pp. 285-287. Lancaster: MTP Press.

Simmons, N. A. \& GibBS, F. J. (1979). Campylobacter ssp. in oven-ready poultry. Journal of Infection 1, 159-162.

Skirrow, M. B. (1977). Campylobacter enteritis: a 'new' disease. British Medical Journal 2, 9-11.

SkIRrow, M. B. (1981). Campylobacter enteritis in dogs and cats: a 'new' zoonosis. Veterinary Research Communications 5, 13-19.

Skirrow, M. B. \& Benjamin, J. (1980). '1001' Campylobacters: cultural characteristics of intestinal campylobacters from man and animals. Journal of Hygiene 85, 427-442.

Skirrow, M. B. \& BenJamin, J. (1982). The classification of 'thermophilic' campylobacters and their distribution in man and domestic animals. In Campylobacter: Epidemiology, Pathogenesis and Biochemistry (ed. D. G. Newell), pp. 40-44. Lancaster: MTP Press.

Skirrow, M. B., Fidoe, R. G. \& Jones, D. M. (1981). An outbreak of presumptive food-borne campylobacter enteritis. Journal of Infection 3, 234-236.

SMeltzer, T. I. (1981). Isolation of Campylobacter jejuni from poultry carcases. Australian Veterinary Journal 57, 511-512.

StERn, N. J. (1981). Recovery rate of Campylobacter fetus ssp. jejuni on eviscerated pork, lamb, and beef carcasses. Journal of Food Science 46, 1291-1293.

Sticht-Groh, V. (1982). Campylobacters in pig faeces. In Campylobacter: Epidemiology, Pathogenesis and Biochemistry (ed. D. G. Newell), pp. 259-260. Lancaster: MTP Press.

Svedhem, Å., KaIJSER, B. \& SJögREN, E. (1981). The occurrence of Campylobacter jejuni in fresh food and survival under different conditions. Journal of Hygiene 87, 421-425. 
Turnbull, P. C. B. \& Rose, P. (1982). Campylobacter jejuni and salmonella in raw red meats. Journal of Hygiene 88, 29-37.

Vogt, R. L., Sours, H. E., Barrett, T., Feldman, R. A., Dickinson, R. J. \& Witherell, L. (1982). Campylobacter enteritis associated with contaminated water. Annals of Internal Medicine 96, 292-296.

Waterman, S. C. (1982). The heat-sensitivity of Campylobacter jejuni in milk. Journal of Hygiene 88, 529-533. 